\title{
Impacts of contracted endodontic cavities compared to traditional endodontic cavities in premolars
}

Juan Xia ${ }^{1+}$, Weidong Wang ${ }^{1+}$, Zhengmao Li $^{2}$, Bingpeng Lin ${ }^{3}$, Qian Zhang ${ }^{4}$, Qianzhou Jiang ${ }^{1}$ and Xuechao Yang ${ }^{1 *}$

\begin{abstract}
Background: This study aims to compare the percentage of dentin removed, instrumentation efficacy, root canal filling and load at fracture between contracted endodontic cavities, and traditional endodontic cavities on root canal therapy in premolars.
\end{abstract}

Methods: Forty extracted intact human first premolars were imaged with micro- $C T$ and randomly assigned to the contracted endodontic cavity (CEC) or traditional endodontic cavity (TEC) groups. CEC was prepared with the aid of a 3D-printed template, canals were prepared with a 0.04 taper M-Two rotary instrument, and cavities were restored with resin. Specimens were loaded to fracture in an Instron Universal Testing Machine after a fatigue phase. The data were analyzed by the independent samples $T$ test and Mann-Whitney $U$ test, appropriate post hoc tests.

Results: In the premolars tested in vitro, the percentage of dentin removed in the premolars with two dental roots in the CEC group $(3.85 \% \pm 0.42 \%)$ was significantly smaller $(P<0.05)$ than in the TEC group $(4.94 \% \pm 0.5 \%)$. The untouched canal wall (UCW) after instrumentation for TECs $(16.43 \% \pm 6.56 \%)$ was significantly lower $(P<.05)$ than the UCW $(24.42 \% \pm 9.19 \%)$ for CECs in single-rooted premolars. No significant differences were observed in the increased canal volume and surface areas in premolars between the TEC and CEC groups $(P>0.05)$. CECs conserved coronal dentin in premolars with two dental roots but no impact on the instrument efficacy.

There were no differences between the CEC groups and the TEC groups in the percentage of filling material and voids $(P>0.05)$. In addition, the mean load at failure of premolars did not significantly differ between the CEC and TEC groups and there was no significant difference in the type of fracture $(P>0.05)$.

Conclusion: The results of this study suggest that CEC could not improve the fracture resistance of the endodontically treated premolars. The instrumentation efficacy and the percentage of filling material did not significantly differ between CECs and TECs in premolars.

Keywords: 3D-printed template, Contracted endodontic cavities, Instrumentation efficacy, Root canal filling, Fracture resistance

\footnotetext{
* Correspondence: xcyang@gzhmu.edu.cn

†Juan Xia and Weidong Wang contributed equally to this work.

'Department of Endodontology, Affiliated Stomatology Hospital of

Guangzhou Medical University, Guangzhou key Laboratory of Basic and

Applied Research of Oral Regenerative Medicine, Guangzhou 510182,

Guangdong, China

Full list of author information is available at the end of the article
}

(C) The Author(s). 2020 Open Access This article is licensed under a Creative Commons Attribution 4.0 International License, which permits use, sharing, adaptation, distribution and reproduction in any medium or format, as long as you give appropriate credit to the original author(s) and the source, provide a link to the Creative Commons licence, and indicate if changes were made. The images or other third party material in this article are included in the article's Creative Commons licence, unless indicated otherwise in a credit line to the material. If material is not included in the article's Creative Commons licence and your intended use is not permitted by statutory regulation or exceeds the permitted use, you will need to obtain permission directly from the copyright holder. To view a copy of this licence, visit http://creativecommons.org/licenses/by/4.0/ The Creative Commons Public Domain Dedication waiver (http://creativecommons.org/publicdomain/zero/1.0/) applies to the data made available in this article, unless otherwise stated in a credit line to the data. 


\section{Background}

Endodontic treatment is a procedure that consists of several steps aiming to retain the normal function of the treated tooth or prevent or heal the periapical periodontitis. The principle of access and coronal cavity preparation is the straight-line pathways into root canals to enhance instrumentation efficacy and prevent complications $[1,2]$. The treatment associated loss of tooth structure could undermine the biomechanical responses of the tooth [3], especially in endodontically treated teeth [4].

Today, materials and novel concepts, including the development of nickel-titanium instruments and the concept of minimally invasive endodontics (MIE), are rapidly changing. MIE is characterized by "systematic respect for the original tissue" and "preventing or treating disease with as little loss of original tissue as possible [5].

Contracted endodontic cavities (CECs), which were inspired by the concepts of MIE, emphasize endodontically treated tooth structure preservation, including pericervical dentin (PCD). The preservation of PCD is important for dental structure and is associated with a long-term survival benefit [6].

Three-dimensional (3D) printing is widely used for preoperative planning and procedure rehearsal [7], orthognathic surgery [8], custom prosthetic design [9], endodontics [10, 11] and surgical guidance [12]. Besides, it would be a useful educational tool for teaching and to enhance communication between the patient and doctors. 3D printing technology could achieve precise design, positioning, and good communication before the operation. Therefore, this technology has been applied in a clinic more extensively to achieve good treatment outcomes [13, 14], besides the accuracy and safety for 3D printed template have been proved $[15,16]$. This research was aimed to design the $3 \mathrm{D}$ printed template for endodontic cavities and explore the clinical significance of 3D printed template in endodontics.

In this study, systematic measurement, including, the percentage of dentin removed, instrumentation efficacy, the increased canal volume and surface areas, the increased sectional area, the percentage of the filling material, and fracture resistance of premolars was conducted. We systematic compare the effect of the percentage of the filling material and fracture resistance of premolars with contracted endodontic cavities.

\section{Methods}

\section{Selection of teeth}

The present study was approved by the Ethics Committee of the Hospital of Stomatology, Guangzhou Medical University (KY-2017-012). Forty human first premolars from an orthodontic tooth extraction in the oral and maxillofacial surgery department were collected extracted, informed written consent was obtained from each patient. Soft and hard tissue residuals on the surfaces of the teeth were removed using an ultrasonic scaler. All teeth had a fully formed apex without any defects or cracks on the surface and had no history of restoration. A curvature of 0-20 $0^{\circ}$, according to Schneider [17] on buccolingual and mesiodistal radiographs was selected. The selected teeth were of similar dimensions. The evaluation of the sample selection was done by computerized microcomputed tomography, All teeth were numbered and assigned into four groups ( $n=10$ / each group) according to the random number table. CEC groups, Group 1: single-rooted mandibular first premolars with one root canal, Vertucci's classification typeI; Group 2: two-rooted maxillary first premolars with double root canals, Vertucci's classification type IV. TEC groups, Group 3: single-rooted mandibular first premolars with one root canal, Vertucci's classification typeI; Group 4: two-rooted maxillary first premolars with double root canals, Vertucci's classification type IV. All the datas were evaluated using CBCT. There was no statistically significant difference $(P>0.05)$ in $\mathrm{BL}, \mathrm{MD}$, or tooth root length between the CEC and TEC groups. The teeth were kept in $1 \%$ chloramine $\mathrm{T}$ trihydrate at room temperature until use.

\section{Manufacture of 3D-printed template}

The guided access cavity was prepared using cone-beam computed tomography and optical surface scans. A highresolution cone-beam computed tomography (CBCT) scan was taken to determine the exact location of the root canal. The drill was virtually superimposed on the root canal to plan the CEC outlines by projecting the access trajectory in each canal orifice that required the least tooth structure removal in Simplant (SIMPLANT, Materialise Dental, Leuven, Belgium) (Fig. 1). The data were then imported into Freeform (Geomagic Freeform, 3D Systems, Morrisville, North Carolina, USA). According to the location of the drill in Simplant, we made a guide template with straight-line pathways into the tooth canal. Additionally, we also designed a 3D printed cylindrical lampstand with a $0.2 \mathrm{~mm}$ gap to simulate the periodontal ligament for every specimen. The digitally designed template and 3D printed cylindrical lampstand were exported as STL-file and then were sent to a 3D printer (3D System 3510HB, 3D Systems, Morrisville, North Carolina, USA).

\section{Root canal preparation between TECs and CECs}

First of all, the teeth were imaged with micro-CT (SkyScan 1172; Bruker micro-CT, Kontich, Belgium) imaging at $20 \mu \mathrm{m}$ (pretreatment scan) to capture the original canal shape and volume of tooth tissue. In CEC preparation, a 3D-printed template was positioned on the tooth model (Fig. 1), and a guiding sleeve was placed on the hole.

CECs were drilled with long diamond burs (MANI SF11, MANI INC, Japan) at high speed. The CEC access attested the distal and mesial accesses could be directed 

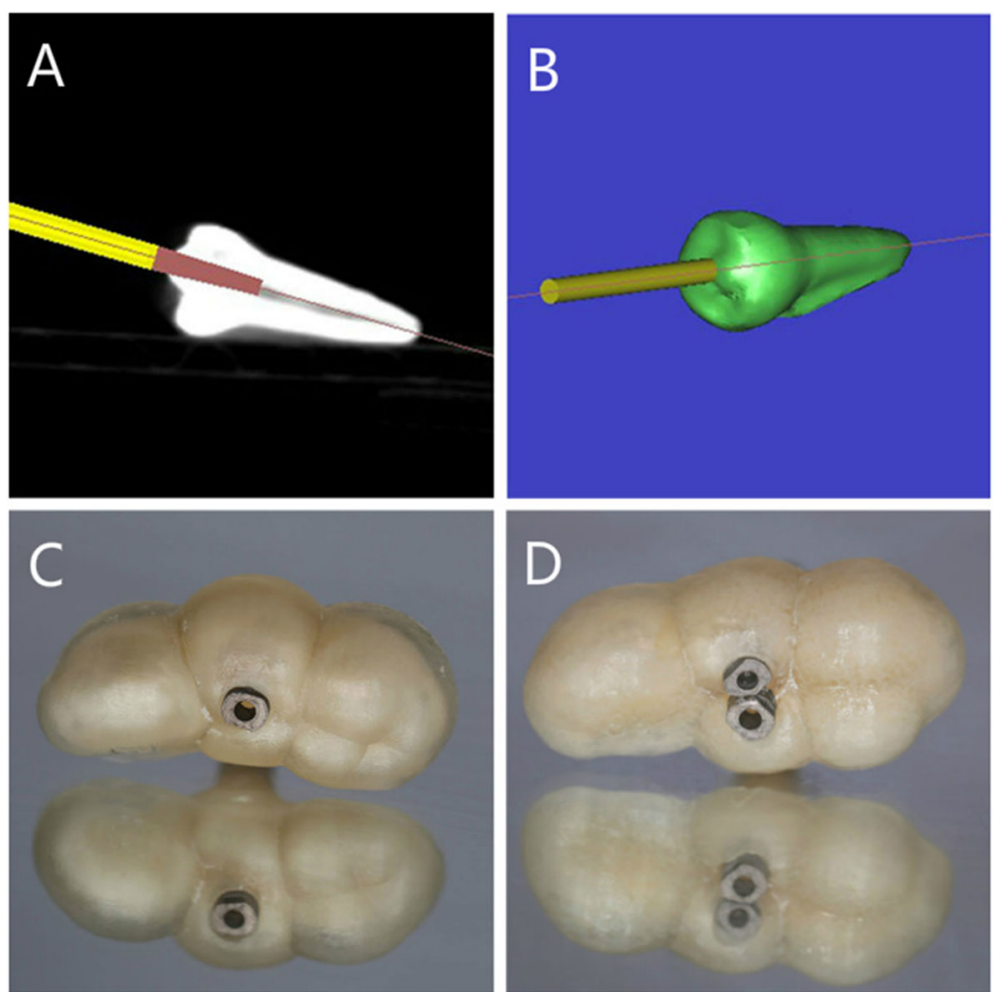

Fig. 1 a The drill virtually superimposed on the tooth to create straight-line access to the apical third of the root canal. b A schematic of a drill in the tooth model. c A 3D-printed template positioned on the single-rooted premolar model. $\mathbf{d}$ Template positioned on the premolar with two dental roots

towards their respective orifices, which kept back the truss of dentin between the cavities. In the TEC group, conventional access cavities were prepared. After initial preparation with pathfile instruments (Dentsply Maillefer, Ballaigues, Switzerland), canals were prepared with 0.04 taper M-Two rotary instruments (VDW company, Munich, Germany) to size 35\#. These instruments were used in a standard technique, The canals were irrigated with $3 \mathrm{ml}$ of 5.25\% sodium hypochlorite (Guangzhou Hui Fan company, Guangzhou, China) between use of each instrument, and then, each canal was irrigated with $5.25 \%$ sodium hypochlorite followed by irrigation for $30 \mathrm{~s}$ with ultrasonic oscillation tip (K15/21-25, SATELEC, France) coupled with an ultrasound device (SATELEC P5XS, Merignac, France) at power 7 . After cleaning and shaping, the teeth were imaged again with micro-CT imaging at $20 \mu \mathrm{m}$ (posttreatment scan) to capture the instrumented canal shape and volume of tooth tissue for comparative the differences. All canals were obturated with gutta-percha cones (Dentsply Sirona, New York, Pennsylvania, USA) and AH Plus sealer (Dentsply DeTrey, Konstanz, Germany). The thermoplastic continuous wave of condensation technique was used for obturation using a B\&L-beta Gutta Percha Heating System (B\&L Biotech, Inc., Korea). Smart Dentin Replacement (Dentsply, DE, USA) was used to imitate the lost dentin tissue, and $2 \mathrm{~mm}$ composite resin restorative material (SHOFU, Kyoto, Japan) was placed on the canal opening. The teeth were stored in physiological saline at $37^{\circ} \mathrm{C}$ for 1 week. After that, each specimen was subjected to micro-CT imaging at $20 \mu \mathrm{m}$ (finished scan).

\section{Load at fracture}

After root canal filling and micro-CT scanning, teeth with a 3D printed cylindrical lampstand were mounted in an Instron Testing machine (E3000, Instron, High Wycombe, UK). The specimens were subjected to 500000 loading cycles in the Instron Testing machine (E3000) axial forces, directed at a 135 angle from the long axis of the tooth [18], between $5 \mathrm{~N}-50 \mathrm{~N}$ at $15 \mathrm{HZ}$ to simulate approximately 2 years of chewing function $[19,20]$. After this fatigue phase, the specimens were placed in the Instron Universal Testing machine (E3366, Instron, MA, America). Each tooth was loaded at the central fossa at $135^{\circ}$ from the tooth long axis to simulate a maximum bending motion of the tooth at buccal cervical areas [8]. A continuous compressive force was applied with a $2-\mathrm{mm}$ spherical crosshead at $1 \mathrm{~mm} / \mathrm{min}$ until failure occurred, which was defined as a $25 \%$ drop in the applied force [21] (Fig. 2a). The load at fracture was recorded in Newton $(\mathrm{N})$, and the type of fracture was recorded (Fig. 2b). 


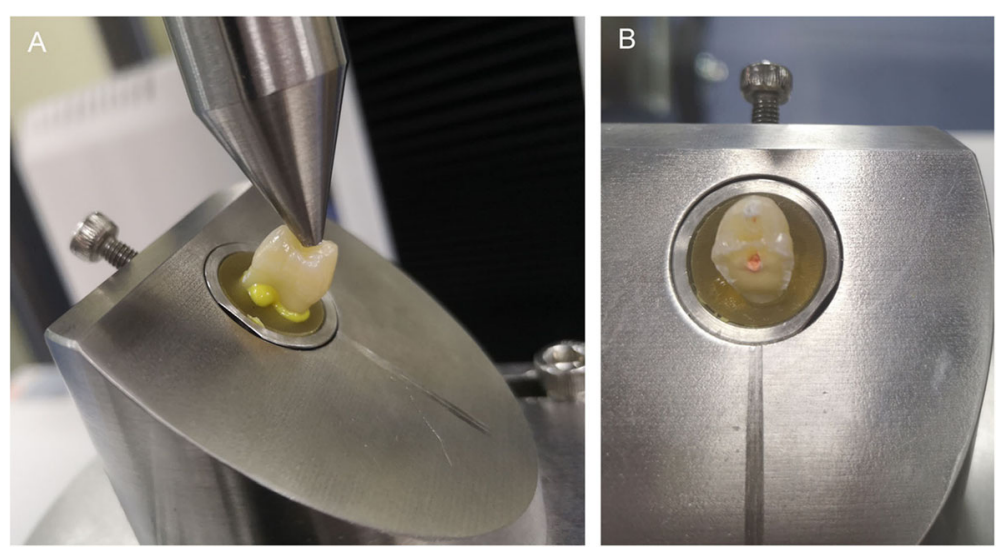

Fig. 2 a Specimens placed in the Instron Universal Testing Machine. $\mathbf{b}$ The fractured tooth and the type of fracture was recorded

\section{Evaluation methodology}

After reconstruction with NRecon (Bruker micro CT, Kontich, Belgium) software, the volume of the tooth tissue was analyzed with CT-AN software (Bruker micro CT, Kontich, Belgium), we selected appropriate CT value as the segmentation of tooth volume. After the pretreatment scan and post-treatment scan were aligned in Data Viewer software (Bruker micro CT, Kontich, Belgium), the increased canal volume and surface areas after root canals shaped during the two different access opening procedures were measured using CT-An software. The proportion of untouched canal wall (UCW) in the canals was determined with 3-Matic (Fig. 3), and we measured the sectional section of 1,3 , and $5 \mathrm{~mm}$ from the apical and the deviation of the central point in Solid Work (Dassault, France) (Fig. 4). The percentage volume of root filling materials and any voids inside the region of interest were calculated in CT-An software, and all areas without filling within the root canal space were considered voids.

\section{Statistical analysis}

The data were analyzed using IBM SPSS Statistics 16 software (Armonk, NY, USA), it was compared with independent samples T-tests, and the Mann-Whitney U test, $P<.05$ was considered significant.

\section{Results}

The percentage of dentin removed in the premolars with two dental roots in the CEC group $(3.85 \% \pm 0.42 \%)$ was significantly smaller $(P<0.05)$ than in the TEC group $(4.94 \% \pm 0.5 \%)$. The UCW after instrumentation for TECs $(16.43 \% \pm 6.56 \%)$ was significantly lower $(P<0.05)$ than the UCW $(24.42 \% \pm 9.19 \%)$ for CECs in singlerooted premolars (Table 1). No significant differences were observed in the increased canal volume and surface areas in premolars between the TEC and CEC groups $(P>0.05)$. In the premolars with two dental roots, the increased sectional area of 1,3 , and $5 \mathrm{~mm}$ from the major apical foramen was significantly greater $(P<0.05)$ in the CEC group than in the TEC group. The deviation of the central point after instrumentation for TECs was significantly smaller $(P<0.05)$ than that for CECs. There was no significant difference $(P>0.05)$ between the TEC and CEC groups in the increased sectional area and the deviation of the central point in single-rooted premolars. Micro-CT analysis revealed that there were no differences between the CEC groups and the TEC groups in

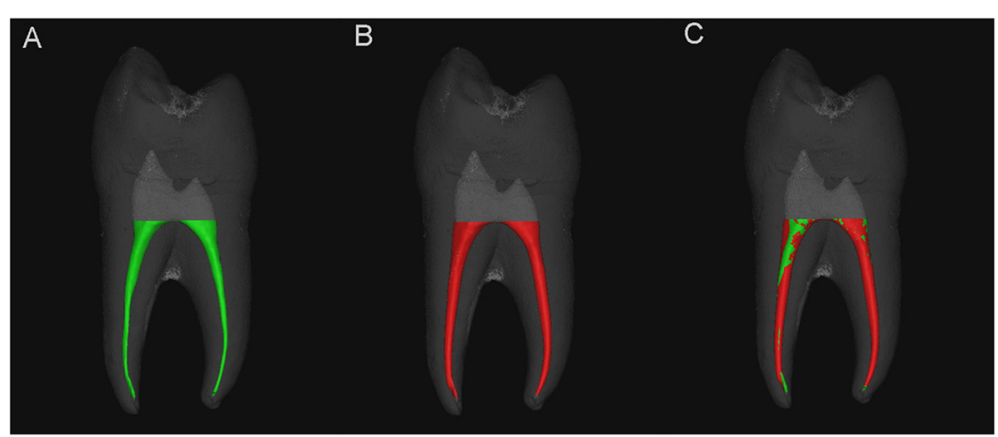

Fig. 3 Preoperative (green) (a), postoperative (red), b and the aligned root canal (c) in 3-matic 


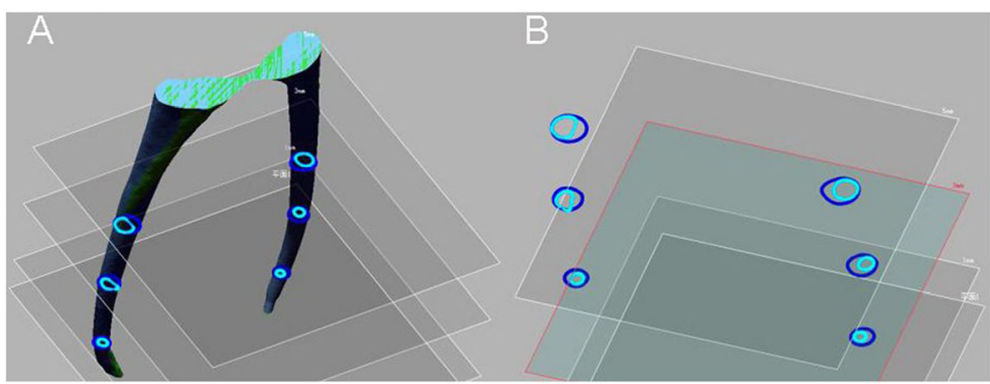

Fig. 4 a The 1, 3, and $5 \mathrm{~mm}$ section from the apical. b The deviation of central point in Solid Work. Preoperative (aquamarine) and postoperative (mazarine)

the percentage of filling material and voids $(P>0.05)$ (Table 2). In general, the mean load at failure of premolars did not significantly differ between the CEC and TEC groups, and there was no significant difference in the type of fracture $(P>0.05)$ (Table 3$)$.

\section{Discussion}

Mininally invasive endodontics is widely accepted nowadays and attracted extensive attention. With the development of advanced equipments and techniques, such as $\mathrm{CBCT}$, dental microscope, nickel-titanium instrument, as well as the single-cone technique. According to the concept, tooth structure preservation turn out to be the prime concern during an endodontic procedure. Recently, contracted endodontic cavity has been put forward to protect dental tissue as much as possible. However, this may lead to difficulty in operating due to the small operating space, insufficient visible light, and may also cause apical transportation, ledge, and instrument fracture. By analysis and compare systematically for the impact of contracted endodontic cavities and traditional endodontic cavities in premolars, the present study aims to provide references and advice to clinicians.

The result suggested that apical transportation after instrumentation for CEC was significantly bigger $(P<$ $0.05)$ than TECs in premolars with two dental roots, and no instrument fracture was experienced, which means although the apical transportation of CEC was bigger in premolars with two dental roots, with the appropriate straight path to a root canal, there is a small probability that instrument fracture occurred in premolars. There was no significant difference $(P>0.05)$ between the TEC

Table 1 Unmodified canal wall after CEC or TEC preparation and root canal instrumentation in premolars assessed by MicroCT imaging

\begin{tabular}{llll}
\hline Tooth type $(n=10)$ & \multicolumn{2}{l}{ UCW (\% of total canal wall surface) } & $\boldsymbol{P}$ value \\
\cline { 2 - 3 } & CEC & TEC & \\
\hline Single-rooted premolars & $24.42 \pm 9.19 \%$ & $16.43 \pm 6.56 \%$ & 0.038 \\
Two dental root premolars & $18.62 \pm 5.85 \%$ & $21.28 \pm 8.91 \%$ & 0.441 \\
\hline
\end{tabular}

and CEC groups in the increased sectional area and the deviation of the central point in single-rooted premolars, which means it is safe and effective in single-rooted teeth.

Contracted endodontic cavities (CECs), as an alternative to traditional endodontic cavities, have been researched widely. So far, the outcomes and fracture resistance of CECs on root canal preparation still limited and controversial. Some studies showed that there was no difference between CECs and TECs in mean failure load in maxillary molars [22]. The type of access cavity does not influence the amount of remaining pulp tissue in root canals and isthmus in maxillary first molars [23]. Similarly, TECs lead to better preservation of the original canal anatomy in maxillary first permanent molars [24]. Most of the previous researches were focused on the efficacy of CECs and TECs treatment in maxillary molars, rarely in premolars. Firstly, the anatomy of premolars is complex and variation; secondly, the concentration of masticatory forces in premolars is big and the cervical of premolars is small; last but not least premolars are more likely to break after root canal therapy; therefore, minimally invasive endodontics in premolars is of great significance.

It is reported that guided endodontics printed templates have been used to locate all root canals in the apical third of teeth with pulp canal calcification and apical pathology with the aid of 3D printing technology and digital dentistry $[16,21]$. In this research, we used guided endodontics printed templates for minimal cavity access, which acquired the least tooth structure removal and projected the access trajectory to each canal orifice. Contracted endodontic cavity with the aid of 3D-printed template seems to be a safe, clinically feasible method for locating root canals.

A previous study reported that CEC seems to exhibit better preservation of the original canal anatomy, particularly at the crown level, including incisors, premolars, and molars with TEC [25]. The conservative endodontic cavity, which could keep back the truss of dentin between the cavities, could save more dental 
Table 2 Mean values \pm standard deviations of the filling material and voids volume in premolars assessed by Micro-CT imaging

\begin{tabular}{|c|c|c|c|}
\hline Groups & Region & Filling material (\%) & Voids (\%) \\
\hline \multirow[t]{4}{*}{ TEC (single-rooted premolars) } & All & $95.35 \pm 2.94$ & $4.65 \pm 2.94$ \\
\hline & Cervica & $94.52 \pm 3.69$ & $5.48 \pm 3.69$ \\
\hline & Middle & $96.28 \pm 2.72$ & $3.72 \pm 2.72$ \\
\hline & Apical & $96.53 \pm 3.72$ & $3.47 \pm 3.72$ \\
\hline \multirow[t]{4}{*}{ CEC (single-rooted premolars) } & All & $96.78 \pm 1.81$ & $3.23 \pm 1.81$ \\
\hline & Cervical & $96.83 \pm 1.76$ & $3.17 \pm 1.76$ \\
\hline & Middle & $97.36 \pm 2.73$ & $2.64 \pm 2.74$ \\
\hline & Apical & $98.29 \pm 1.51$ & $1.71 \pm 1.51$ \\
\hline \multirow[t]{4}{*}{ TEC (two dental roots premolars) } & All & $91.59 \pm 3.48$ & $8.41 \pm 3.48$ \\
\hline & Cervical & $89.82 \pm 4.1$ & $10.18 \pm 4.1$ \\
\hline & Middle & $95.34 \pm 3.27$ & $4.66 \pm 3.27$ \\
\hline & Apical & $95.07 \pm 5.13$ & $4.93 \pm 5.13$ \\
\hline \multirow[t]{4}{*}{ CEC (two dental roots premolars) } & All & $91.07 \pm 6.38$ & $8.93 \pm 6.38$ \\
\hline & Cervical & $88.45 \pm 9.06$ & $11.55 \pm 9.06$ \\
\hline & Middle & $93.75 \pm 5.55$ & $6.25 \pm 5.55$ \\
\hline & Apical & $96.87 \pm 3.49$ & $3.13 \pm 3.49$ \\
\hline
\end{tabular}

CEC contracted endodontic cavity, TEC traditional endodontic cavity

No statistically significant difference was observed between groups throughout the canal in each region $(p>.05)$

tissue in premolars with two dental roots. Although more tooth tissue was retained, there was no obvious increase in the fracture resistance. It is probably because the volume of premolars themselveswas small, the increased fracture resistance of reserved coronal dentin could not offset the decreased amount that caused by RCT. Hence, further studies and a larger amount of simples are needed.

According to Neelakantan'report, Root canal was divided into coronal, middle and apical apart [18]. In the present research, due to similar sample size, it could avoid the difference of measurement and analysis caused by the differences of sample length.

Canal and crown boundaries were demarcated at the buccal-lingual level of the cementoenamel junction in single-rooted premolars, and canal boundaries were demarcated in root separation in premolars with two dental roots, all analyses were calculated separately for the cervical, middle, and apical thirds of the canal. MicroCT allowed the 3D anatomy assessment of root canal fillings and voids, the results obtained in our study did

Table 3 Load at fracture (mean values \pm standard deviations) for premolars with CEC or TEC assessed in the Instron Universal Testing Machine

\begin{tabular}{llll}
\hline Tooth type $(n=10)$ & \multicolumn{2}{l}{ UCW (\% of total canal wall surface) } & $P$ value \\
\cline { 2 - 3 } & CEC & TEC & \\
\hline Single-rooted premolars & $926.90 \pm 194.97$ & $888.57 \pm 165.73$ & 0.64 \\
Two dental root premolars & $665.09 \pm 168.74$ & $630.95 \pm 159.81$ & 0.88 \\
\hline
\end{tabular}

not show obvious differences in the percentage of root canal filling in the CEC and TEC groups. Although the entrance of the pulp chamber is smaller in CECs, with the straight-line pathways into canals, the root canal filling can be completed for both CECs and TECs equally.

Numerous studies provided CEC preparation did not increase the fracture strength of teeth compared with TEC preparation [26-28]. This result corroborate with those above research. The researchers have found the endodontic procedures do not weaken teeth with intact marginal ridges [29], the CEC and TEC groups were both prepared with intact marginal ridges, and there were no significant differences $(P>0.05)$ on biomechanical responses between the premolars in the CEC and TEC groups. At the same time, the result was opposite to Krishan's research [30], which reported CEC increased fracture resistance in premolars and mandibular molars. The following 4 explanations clarify this contradiction: (1) the simulated clinical treatment procedure to restore the access cavities with resin before fracture resistance test; (2) the angle of the tooth loaded at the central fossa from the tooth long axis and the spherical crosshead was different in this study; (3) single-rooted premolars and premolars with two dental roots were differentiated; (4) each sample has been tested by fatigue cycle test. All of these factors have a potential effect on the final results. In addition, the load type was comparable to that experienced in the mouth, and human teeth were subjected to forces in different directions at the same time, the tested teeth have irregular shapes, and 
the experimental data acquired were just in one direction, and the results were for reference. Besides, when we discuss about CECs, the extended preparation time and materials should be considered.

\section{Conclusions}

Within the limitations of this study, the current results did not show obvious benefits associated with the CEC group compared with the TEC group. Although CECs could conserve more tooth hard tissue, the results of this study did not suggest that CEC could improve the fracture resistance of the endodontically treated premolars. The instrumentation efficacy and the percentage of filling material did not significantly differ between CECs and TECs in the premolars. Future experiments with bigger sample sizes and long-term clinical studies are encouraged to carry out on this topic.

Besides, contracted endodontic cavity with the aid of 3D-printed template seems to be a safe, clinically feasible method for locating root canals, which could be a prosperous future in minimally invasive endodontics.

\section{Abbreviations}

CEC: Contracted endodontic cavity; TEC: Traditional endodontic cavity; 3D: Three-dimensional; MIE: Minimally invasive endodontics; PCD: Pericervical dentin; CBCT: Cone-beam computed tomography; RCT: Root canal therpy; Micro-CT: Micro computed tomography

\section{Acknowledgements}

Not applicable.

\section{Authors' contributions}

$X C Y$ come up with this idea. JX and WDW designed and manufactured the $3 \mathrm{D}$ printed template. JX and ZML were participated in the analytical CT data. QZJ was participated in the clinical operation. QZ and BPL were responsible for the literature search and wrote the paper. All authors read and approved the final manuscript.

\section{Funding}

This work was supported by the National Key R\&D Program of China (No. 2018YFB116903), the International Cooperation from the Science and Technology Planning Project (No. 2017A050501054), the Medical Research Foundation of Guangdong province (No. A2017583), and the project of 2018 annual Guangdong Higher Education Reform Project (No.2018-486).

\section{Availability of data and materials}

The datasets used and/or analysed during the current study are available from the corresponding author on reasonable request.

\section{Ethics approval and consent to participate}

This study was approved by the Ethics Committee of the Hospital of Stomatology, Guangzhou Medical University and written informed consent was obtained from the participants.

\section{Consent for publication}

Not applicable.

\section{Competing interests}

The authors declare that they have no competing interests.

\section{Author details}

'Department of Endodontology, Affiliated Stomatology Hospital of Guangzhou Medical University, Guangzhou key Laboratory of Basic and Applied Research of Oral Regenerative Medicine, Guangzhou 510182, Guangdong, China. ${ }^{2}$ Department of Basic Science of Stomatology, Affiliated
Stomatology Hospital of Guangzhou Medical University, Guangzhou key Laboratory of Basic and Applied Research of Oral Regenerative Medicine, Guangzhou 510182, Guangdong, China. ${ }^{3}$ Department of Orthodontic, Affiliated Stomatology Hospital of Guangzhou Medical University, Guangzhou key Laboratory of Basic and Applied Research of Oral Regenerative Medicine, Guangzhou 510182, Guangdong, China. ${ }^{4}$ Department of Oral Function and Prosthetic Dentistry, College of Dental Science, Radboud University Nijmegen Medical Centre, Philips van Leydenlaan 25, 6525EX Nijmegen, The Netherlands.

Received: 11 August 2019 Accepted: 27 August 2020

Published online: 07 September 2020

\section{References}

1. Schroeder KP, Walton RE, Rivera EM. Straight line access and coronal flaring: effect on canal length. J Endod. 2002;28:474-6.

2. Patel $\mathrm{S}, \mathrm{Rhodes} J$. A practical guide to endodontic access cavity preparation in molar teeth. Br Dent J. 2007:203:133-40.

3. Pereira JR, McDonald A, Petrie A, Knowles JC. Effect of cavity design on tooth surface strain. J Prosthet Dent. 2013:110:369-75.

4. Chen SC, Chueh LH, Hsiao CK, Wu HP, Chiang CP. First untoward events and reasons for tooth extraction after nonsurgical endodontic treatment in Taiwan. J Endod. 2008;34:671-4.

5. Gluskin AH, Peters $\mathrm{Cl}$, Peters OA. Minimally invasive endodontics: challenging prevailing paradigm. Br Dent J. 2014;216:347-53.

6. Clark D, Khademi J. Modern molar endodontic access and directed dentin conservation. Dent Clin N Am. 2010;54:249-73.

7. Chen Y, Jia X, Qiang M, Zhang K, Chen S. Computer-assisted virtual surgical technology versus three-dimensional printing technology in preoperative planning for displaced three and four-part fractures of the proximal end of the humerus. J Bone Joint Surg Am. 2018;100:1960-8.

8. Shaheen $E$, Sun $Y$, Jacobs R, Politis C. Three-dimensional printed final occlusal splint for orthognathic surgery: design and validation. Int J Oral Maxillofac Surg. 2017;46:67-71.

9. Bukhari S, Goodacre BJ, AlHelal A, Kattadiyil MT, Richardson PM. Threedimensional printing in contemporary fixed prosthodontics: a technique article. J Prosthet Dent. 2018;119:530-4.

10. Strbac GD, Schnappauf A, Giannis K, Moritz A, Ulm C. Guided modern endodontic surgery: a novel approach for guided osteotomy and root resection. J Endod. 2017;43:496-5.

11. Ye S, Zhao S, Wang $W$, Jiang $Q$, Yang $X$. A novel method for periapical microsurgery with the aid of 3D technology: a case report. BMC Oral Health. 2018:18:85-9.

12. Ciocca L, De Crescenzio F, Fantini M, Scotti R. CAD/CAM and rapid prototyped scaffold construction for bone regenerative medicine and surgical transfer of virtual planning: a pilot study. Comput Med Imaging Graph. 2009;33:58-62.

13. Krastl G, Zehnder MS, Connert T, Weiger R, Kühl S. Guided endodontics: a novel treatment approach for teeth with pulp canal calcification and apical pathology. Dent Traumatol. 2016;32:240-6.

14. Shi X, Zhao S, Wang W, Jiang Q, Yang X. Novel navigation technique for the endodontic treatment of a molar with pulp canal calcification and apical pathology. Aust Endod J. 2018;44:66-70.

15. Connert T, Zehnder MS, Weiger R, Kühl S, Krastl G. Microguided endodontics: accuracy of a miniaturized technique for apically extended access cavity preparation in anterior teeth. J Endod. 2017;43:787-90.

16. Zehnder MS, Connert T, Weiger R, Krastl G, Kühl S. Guided endodontics: accuracy of a novel method for guided access cavity preparation and root canal location. Int Endod J. 2016;49:966-72.

17. Silva EJNL, Rover G, Belladonna FG, De-Deus G, Da Silveira Teixeira C, Da Silva Fidalgo TK. Impact of contracted endodontic cavities on fracture resistance of endodontically treated teeth: a systematic review of in vitro studies. Clin Oral Investig. 2018;22:109-18.

18. Neelakantan P, Khan K, Hei Ng GP, Yip CY, Zhang C, Pan Cheung GS. Does the orifice-directed dentin conservation access design debride pulp chamber and mesial root canal systems of mandibular molars similar to a traditional access design? J Endod. 2018;44:274-9.

19. Alovisi M, Pasqualini D, Musso E, Bobbio E, Giuliano C, Mancino D, et al. Influence of contracted endodontic access on root canal geometry: an in vitro study. J Endod. 2018;44:614-20. 
20. Schneider SW. A comparison of canal preparations in straight and curved root canals. Oral Surg Oral Med Oral Pathol. 1971;32:271-5.

21. Lara-Mendes STO, Barbosa CFM, Machado VC, Santa-Rosa CC. A new approach for minimally invasive access to severely calcified anterior teeth using the guided endodontics technique. J Endod. 2018;44:1578-82.

22. Goto Y, Nicholls Jl, Phillips KM, Junge T. Fatique resistance of endodontically treated teeth restored with three dowel-and-core systems. J Prosthet Dent. 2005;93:45-50

23. Krejci I, Mueller E, Lutz F. Effects of thermocycling and occlusal force on adhesive composite crowns. J Dent Res. 1994;73:1228-32.

24. Grippo JO, Chaiyabutr Y, Kois JC. Effects of cyclic fatigue stress-biocorrosion on noncarious cervical lesions. J Esthet Restor Dent. 2013;25:265-72.

25. Krishan R, Paqué F, Ossareh A, Dao T, Friedman S. Impacts of conservative endodontic cavity on root canal instrumentation efficacy and resistance to fracture assessed in incisors, premolars, and molars. J Endod. 2014:40:1160-6.

26. Moore B, Verdelis K, Kishen A, Dao T, Friedman S. Impacts of contracted endodontic cavities on instrumentation efficacy and biomechanical responses in maxillary molars. J Endod. 2016;42:1779-83.

27. Özyürek T, Ülker Ö, Demiryürek EÖ, YıImaz F. The effects of endodontic access cavity preparation design on the fracture strength of endodontically treated teeth: traditional versus conservative preparation. J Endod. 2018;44: $800-5$.

28. Rover G, Belladonna FG, Bortoluzzi EA, De-Deus G, Silva EJNL, Teixeira CS. Influence of access cavity design on root CanalDetection, instrumentation efficacy, and fracture resistance assessed in maxillary molars. J Endod. 2017; 43:1657-62.

29. Reeh ES, Messer HH, Douglas WH. Reduction in tooth stiffness as a result of endodontic and restorative procedures. J Endod. 1989;15:512-6.

30. Krishan R, Paqué F, Ossareh A, Kishen A, Dao T, Friedman S. Impacts of conservative endodontic cavity on root canal instrumentation efficacy and resistance to fracture assessed in incisors, premolars, and molars. J Endod. 2014;40:1160-6.

\section{Publisher's Note}

Springer Nature remains neutral with regard to jurisdictional claims in published maps and institutional affiliations.

Ready to submit your research? Choose BMC and benefit from:

- fast, convenient online submission

- thorough peer review by experienced researchers in your field

- rapid publication on acceptance

- support for research data, including large and complex data types

- gold Open Access which fosters wider collaboration and increased citations

- maximum visibility for your research: over $100 \mathrm{M}$ website views per year

At $\mathrm{BMC}$, research is always in progress.

Learn more biomedcentral.com/submissions 